Proceedings of the Institution of
Civil Engineers
Municipal Engineer 157
September 2004 Issue ME3
Pages 193-197
Paper 13569
Received 13 November 2003
Accepted 4 March 2004
Keywords:
Landfill/sewage treatment \&
disposal

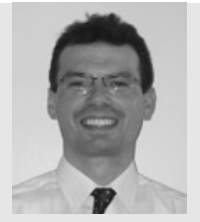

Brendan C. O'Kelly

Lecturer in Civil Engineering

University of Dublin, Trinity

College, and formerly Scott

Wilson, UK

\title{
Geotechnical aspects of sewage sludge monofills
}

\section{B. C. O'Kelly PhD, MEngSc, CEng}

More stringent controls on the quality of wastewater discharges are giving rise to increasing volumes of sewage sludge for disposal. Within the European Community, the disposal of sewage sludge to sea ceased by 1998 under the Urban Wastewater Treatment Directive. Stricter waste disposal legislation and higher landfill taxes are forcing the water industry to look for more efficient disposal strategies. Dedicated sludge-to-landfill operations are presented as a viable option. The sewage sludge is dewatered to the optimum water content for compaction, placed in the landfill in layers and compacted to the maximum dry density, thereby maximising the operational life of the landfill site. The design, construction and long-term performance of such monofills are described. Adequate levels of dewatering for the sludgeto-landfill route can best be achieved at the treatment plant using conventional mechanical dewatering devices, sludge drying beds or thermal drying processes.

\section{INTRODUCTION}

Sewage sludge is the concentrated slurry of mainly clay-sized particles derived from wastewater treatment processes. More stringent controls on the quality of wastewater discharges, for instance, the Urban Wastewater Treatment Directive, ${ }^{1}$ have given rise to increasing volumes of the sludge for disposal. The principal disposal routes available are land spreading, sludge-tolandfill and incineration. The preferred route has been the spreading of the liquid sludge on land to act as a fertiliser and soil conditioner. However, landfill disposal is currently the principal disposal route used within the European Community. The dewatered sludge material is usually mixed with other solid waste in municipal landfills. Thermal drying and incineration of the sludge material are also being increasingly used as intermediate treatments before final disposal of the sludge ash, generally to landfill.

Some European countries currently have no municipal waste incineration plants, largely due to planning difficulties, public opposition and concerns over possible emissions of toxic substances such as dioxins in the flue gas. Hence, at least in the short to medium term, the importance of the sludge-to-landfill route will increase, particularly in countries without the incineration route. Increasingly, however, landfill licences specifically prohibit co-disposal of liquid sewage sludge, for example new licences granted in Ireland under the Waste Management $\mathrm{Act}^{2}$ by the Environmental Protection Agency. Operators of existing landfills are also increasingly reluctant to accept dewatered sewage sludge due to concerns about sludge handling, trafficability and instability of the landfill slopes. Increasingly strict legislation, higher landfill taxes and increased competition for landfill space are causing the water industry to look for more effective strategies for sludge disposal.

The paper considers dedicated sludge-to-landfill operations which involve placement of the sludge material in layers and compaction to the maximum dry density, thereby maximising the operational life for the landfill site. The liquid sludge is dewatered and dried at the wastewater treatment plant to the optimum water content for compaction in the landfill.

Substantial reductions in the cost of trucking the sludge to the landfill are achieved by the drying process. Leachate production at the landfill also decreases significantly. However, biologically stabilised sludge, generally achieved by sludge thickening and digestion processes, ${ }^{3}$ is required. 0 'Kelly ${ }^{4}$ reported some engineering properties of anaerobically digested sewage sludge from the Tullamore municipal wastewater treatment plant (Tullamore, Ireland). The treatment plant serves an urban population of approximately 12000 . The results of additional index, compaction, shear strength and compressibility tests are presented and the database of engineering properties applied, in particular to aspects of the design, construction and management of sewage sludge monofills. Since sewage sludge is largely an organic material, consideration is also given to the effects of further microbial decomposition on landfill performance, in particular the reduction in shear strength due to a build-up of pore water and pore gas pressures.

Sludge material from different wastewater treatment plants can have different engineering properties, principally due to different input levels of industrial wastewater. However, the engineering properties of the Tullamore municipal wastewater treatment plant sludge are indicative and are used to demonstrate the technical feasibility of the dedicated sludge-to-landfill disposal route. Further engineering tests should be conducted by the municipal authority to determine the optimum conditions for landfill disposal of sludge material from specific treatment plants.

Sludge consistency can be quantified in terms of water content or solids content. Water content (WC), as used in geotechnical 


\begin{tabular}{|lcr|}
\hline & \multicolumn{2}{c|}{ Performance } \\
\cline { 2 - 3 } Process & Solids content: \% & $\begin{array}{c}\text { Water } \\
\text { content: \% }\end{array}$ \\
\hline Belt filter press & $15-30$ & $230-570$ \\
Centrifuge & $10-35$ & $190-900$ \\
Recessed plate filter press & $20-50$ & $100-400$ \\
Drying beds & $30-60$ & $70-230$ \\
Lagoon & $15-40$ & $150-570$ \\
Table 1. Performance of sewage sludge drying and dewatering \\
\hline processes
\end{tabular}

literature, is defined as the ratio of the mass of pore water to the mass of solid particles in the sludge, expressed as a percentage. The solids content (SC), used in water treatment literature, is defined as the mass ratio of the dry solid particles to the bulk sludge mass, expressed as a percentage. Water content and solids content are related using equation (1)

\begin{tabular}{|l|ll|}
\hline 1 & $\mathrm{SC}=\frac{100}{1+(\mathrm{WC} / 100)} \quad(\%)$ \\
\hline
\end{tabular}

Table 1 lists the performance of drying and mechanical dewatering processes. The principal mechanical dewatering devices are the belt filter press, recessed plate filter press, and centrifuge. ${ }^{3}$ Chemical agents, which are added to the liquid sludge to act as conditioning agents, enhance sludge dewaterability. Their performance is expressed in terms of the final water content (solids content) ranges achievable. The recessed plate filter press produces the highest cake solids concentration of the mechanical dewatering devices.

\section{PHYSICAL PROPERTIES}

Sewage sludge is an organic slurry of which typically $90 \%$ dry mass passes the $425 \mu \mathrm{m}$ sieve. The sludge plasticity characteristics are similar in some respects to those of peat having a high degree of humification. Ongoing microbial decomposition of the volatile solids reduces the sludge organic content which typically ranges from $70 \%$ dry mass for the raw sludge, to $45 \%$ dry mass for strong digestion. The specific gravity of solids increases due to the relative increase in the proportion of denser inert particles that comprise the sludge. The specific gravity of solids values are low, typically between 1.5 and 1.7 . The sludge generally continues to digest slowly following treatment at the wastewater plant. Tests on bulk samples indicated that digestion was still ongoing two and a half years after a moderate level of biological treatment at the plant. Biogas and leachate are by-products of sludge digestion. Tests indicated that biogas can evolve at rates of up to 0.3 litres biogas $/ \mathrm{day} / \mathrm{kg}$ moderately digested sludge disposed to landfill.

\section{DRYING AND COMPACTION}

Figures 1 and 2 show density-water content data for the digested sludge material achieved by standard Proctor compaction and natural evaporation processes. Bulk density and dry density values are low, but in line with the low specific gravity of solids values. Slightly higher density values are achieved overall for greater levels of sludge digestion. If all the air in a soil could be expelled by compaction, the soil would be in a state of full saturation and the dry density would be the maximum possible

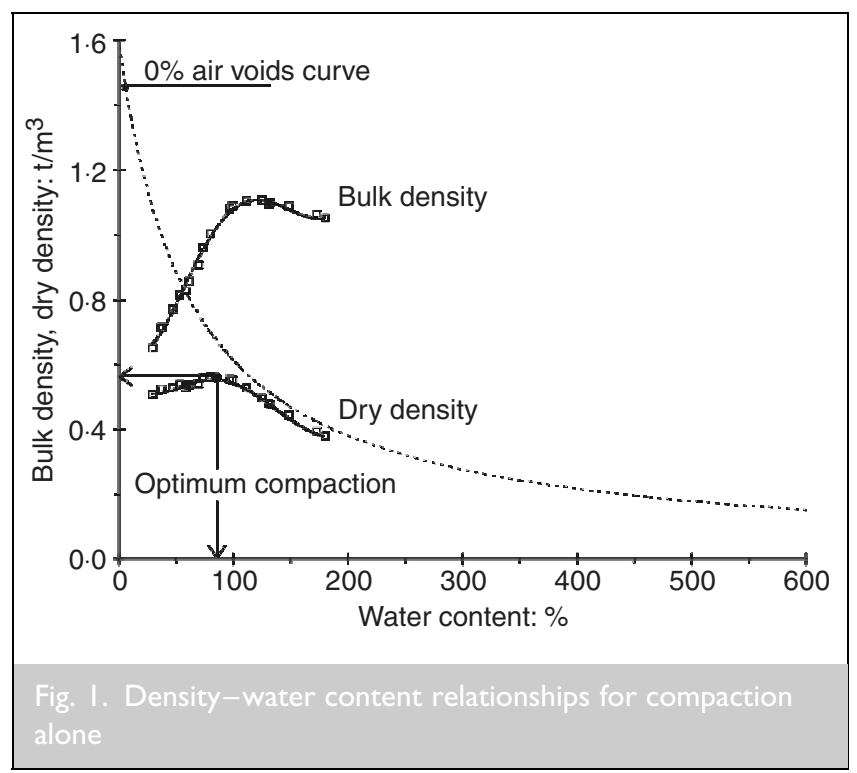

value for the given water content. The zero air voids curve included in these figures indicates the theoretical upper bound for the dry density that can be achieved.

\section{I. Soil density achieved by compaction}

The density achieved by standard Proctor compaction of the partially dried sludge material is given by the curves shown in Fig. 1. These data are pertinent to the control of compaction operations at dedicated landfills where the sludge material is built up in layers. The maximum dry density of $0.56 \mathrm{t} / \mathrm{m}^{3}$ is produced for compaction at approximately $85 \%$ WC ( $54 \%$ SC). Sludge material drier than $85 \%$ WC compacts poorly. Soil laboratory tests indicated that the sludge loses its adhesion below approximately 95\% WC. Hence, handling and compaction operations are most efficiently conducted between $85 \%$ and 95\% WC. The water content of the treatment plant sludge can be reduced to within this WC range using the recessed plate filter press device in conjunction with sludge conditioning, or alternatively using sludge drying beds or thermal drying processes (Table 1).

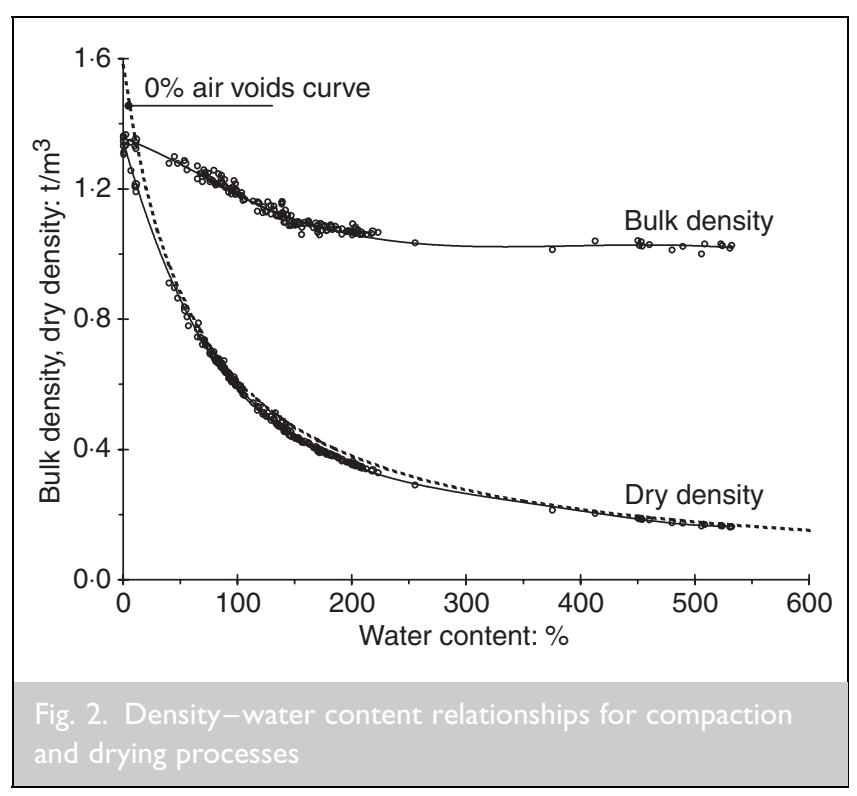


Standard Proctor compactive effort, the level of soil compaction generally used in practice, results in overcompaction of the partially dried sludge material. Some swelling and softening of the compacted material will occur. Hence, a lighter compactive effort is recommended in practice. Loll, ${ }^{6}$ for example, recommended using a compactive effort of approximately onethird that of standard Proctor compactive effort when preparing sludge specimens for laboratory shear strength tests. Field trials may refıne this estimate.

\subsection{Soil density achieved by natural evaporation}

Further tests were conducted to determine the density produced by natural evaporation. The density produced by air-drying of sludge material that had been compacted at between 85\% and 95\% WC and air-drying alone of the sludge from the liquid state is given by the curves shown in Fig. 2. These data are pertinent to the drying of compacted sludge material in situ and drying of liquid sludge in drying beds and lagoons. Significantly higher densities are achieved by air-drying the sludge material, over compaction alone, below the optimum water content of $85 \%$ for compaction.

Air-drying and consolidation to the equilibrium in situ water content produces significant volume shrinkage of the compacted sludge material. The shrinkage ratio, defined as the ratio of the change in soil volume to the change in water content, is typically 1.4. Stability analysis of the landfill slopes must consider the effects of shrinkage cracks which may open up in the vicinity of the slope crest.

\subsection{Compaction of dry sludge pellets}

Compaction and swell tests were also conducted on thermally dried pellets of sewage sludge which are sometimes disposed to landfill. The dry material compacts poorly since the pellets remain as separate particles. The unconfined swelling capacity was assessed by measuring the increase in volume of a dry sludge powder when deposited in water. ${ }^{7}$ The tests indicated that rehydration of the dry pellets to the equilibrium field WC can cause the soil body to approximately double in volume. This swelling causes softening of the sludge material which can lead to instability of the landfill. Hence, it is recommended that the sludge material should not be dried significantly below the optimum water content for compaction prior to landfill disposal.

\section{SHEAR STRENGTH}

The geometry of the sludge landfill body can lead to significant shear stresses developing in the vicinity of the side slopes. The stability of the landfill slopes is assessed using conventional soil mechanics theory. The analysis must consider the strength parameters relevant to the landfill age, namely

(a) the short-term or end of construction condition

(b) the long-term, biologically stabilised sludge landfill

(c) intermediate conditions where sludge digestion is still ongoing.

The undrained shear strength is pertinent to engineering the efficient disposal and stability during landfill construction. Another important consideration during construction is the ability of the deposit to support heavy machine plant, including landfill compactors and dump trucks. The effective-stress strength properties are used to determine the factor of safety against slope instability for the intermediate and long-term conditions.

Pore pressure variations, which can have a significant influence on stability, must be carefully taken into account in the analysis for the intermediate conditions. Pore water and pore gas pressure variations can occur due to the build-up of leachate and biogas in the landfill body. ${ }^{8}$ It is imperative therefore to have an efficient, well-maintained biogas control system and leachate drainage system.

\section{I. Undrained shear strength properties}

Figure 3 shows the undrained shear strength-WC relationship for the sludge, which was determined using the vane shear apparatus and triaxial compression apparatus. ${ }^{9}$ The sludge material was tested in the liquid, plastic and solid states; test specimens drier than the optimum WC for compaction were prepared by air-drying samples which had been compacted at between $85 \%$ and 95\% WC. The undrained shear strength of these specimens is representative of the shear strength achieved by airdrying and consolidation of the sludge material after optimum field compaction. The undrained shear strength increases exponentially with reducing water content, below approximately $180 \%$ WC (35\% SC). Sludge cake wetter than 180\% WC has negligible shear strength.

Stability is not a concern during landfill construction if the sludge material is compacted within the optimum WC range for compaction of $85-95 \%$ WC. The sludge material has an undrained shear strength of typically $50 \mathrm{kN} / \mathrm{m}^{2}$ over this WC range (Fig. 3).

Good agreement was obtained between the shear strength values measured using the different test apparatus. Hence, the field vane shear test provides a quick and accurate measure of sludge consistency and can be used in practice to assess whether the sludge has been adequately dewatered prior to landfill disposal.

\subsection{Effective-stress strength properties}

The effective-stress strength properties of the sludge material were determined using the consolidated-undrained triaxial

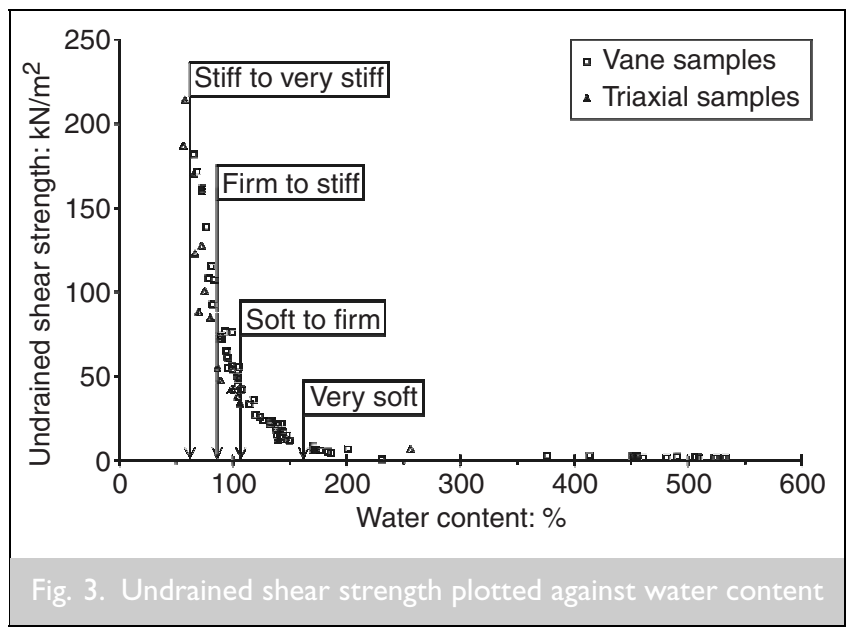


compression test and with measurement of the pore water pressure response. ${ }^{10}$ The test material was pasteurised by heating the liquid sludge to $70^{\circ} \mathrm{C}$ so that the test specimens would remain in a saturated condition, thereby facilitating accurate measurement of the pore pressure response. The specimens were sheared very slowly to allow all pore pressures to equilibrate throughout the sample. The effective angle of internal friction $\left(\phi^{\prime}\right)$ value ranged between $32^{\circ}$ and $37^{\circ}$ for moderate and strong levels of sludge digestion, respectively. The effective cohesion was zero, irrespective of the level of sludge digestion. In practice, biogas and leachate are produced due to ongoing digestion. Although these friction values were measured for neutralised sludge, they can also be used to analyse the long-term factor of safety against slope instability of landfills which incorporate active sludge material providing effective biogas control systems and a leachate drainage system allowing the biogas and leachate to readily escape from the landfill. Values of other engineering properties used in the analysis must relate to the appropriate level of sludge digestion.

\section{DEWATERING AND CONSOLIDATION}

Under the sustained load of the landfill overburden, the sludge will consolidate due to the extrusion of leachate. As the water content decreases, the solids content of the sludge increases, the landfill gradually subsides, and the shear strength of the sludge material increases. The rate of consolidation is controlled by the intrinsic permeability of the sludge.

The consolidation properties of the sludge were studied using the oedometer apparatus and the large hydraulic consolidation cell. ${ }^{9,10}$ Consolidation tests were conducted on the sludge cake and dried sludge material which had been compacted between 85\% and 95\% WC using standard Proctor compactive effort. The duration of the sample loading stages was extended from the standard $24 \mathrm{~h}$ duration to at least $48 \mathrm{~h}$ to assess the consolidation and, in particular, the long-term creep settlement behaviour of dedicated sludge landfills.

The consolidation characteristics of the sludge are summarised using the void ratio-logarithm applied pressure $(e-\log p)$ plot shown in Fig. 4. The void ratio is the ratio of the volume of void

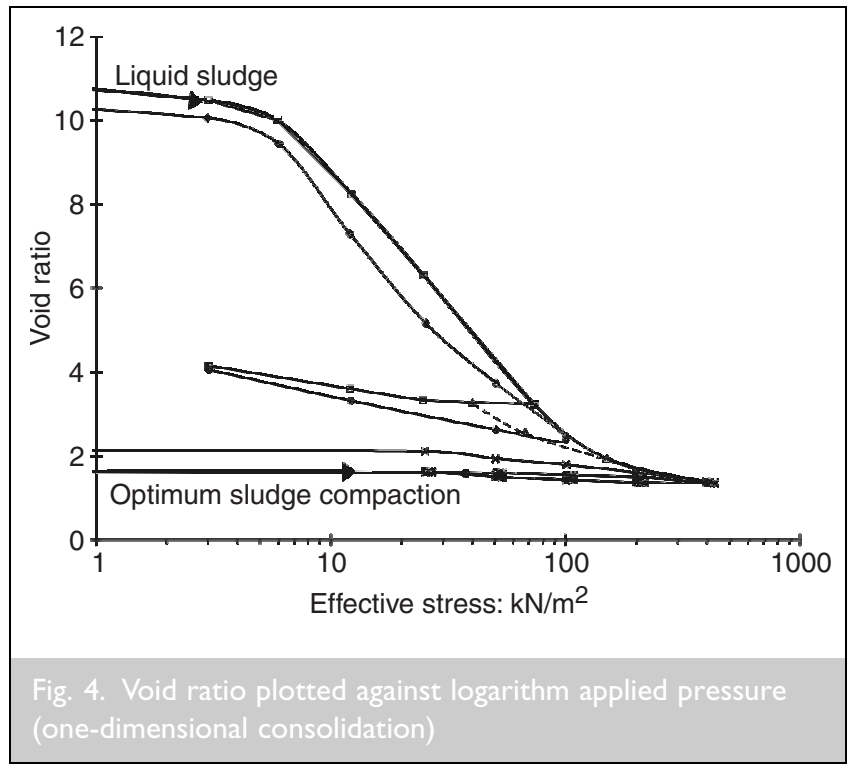

space to the volume of the solid particles. Applied consolidation pressures ranged from as little as $3 \mathrm{kN} / \mathrm{m}^{2}$ for the liquid sludge, to $400 \mathrm{kN} / \mathrm{m}^{2}$ for the compacted sludge material. The slope of the $e-\log p$ curve, defined as the compression index $\left(C_{c}\right)$, relates directly to the compressibility of the sludge material and is used to estimate the total settlement that will occur in the field (equation (2)). Typical values of the compression index are $C_{\mathrm{c}}=7$ for consolidation of the liquid sludge, and $C_{\mathrm{c}}=1$ for consolidation of sludge material compacted at between 85\% and 95\% WC. Leachate drainage systems are designed on the basis of the rate of expulsion of leachate which equals the rate of consolidation of the landfill body.

\begin{tabular}{|l|l|}
\hline 2 & $\Delta H=\frac{C_{\mathrm{c}} H_{\mathrm{o}}}{1+e_{\mathrm{o}}} \log \frac{\boldsymbol{p}_{\mathrm{o}}+\Delta \boldsymbol{p}}{\boldsymbol{p}_{\mathrm{o}}}$ \\
\hline
\end{tabular}

where $\Delta H$ is the anticipated settlement; $H_{\mathrm{o}}$ is the initial depth of the sludge landfill; $C_{\mathrm{c}}$ is the compression index; $e_{\mathrm{o}}$ is the initial void ratio; $p_{\mathrm{o}}$ is the initial applied pressure; and $\Delta p$ is the increase in applied pressure.

Although the sludge material is highly compressible, consolidation generally occurs slowly. The intrinsic permeability of the liquid sludge is low, typically of the order of $10^{-9} \mathrm{~m} / \mathrm{s}$ for moderately digested sludge. However, substantial reductions in permeability during dewatering processes quickly render the sludge material practically impermeable. The flocs of organic clay-sized particles of which the sludge is largely composed trap surface and interstitial water. Hence, the bulk of the landfill settlement occurs due to secondary compression, the creep and decomposition of the solid particles. Primary consolidation, the deformation associated with drainage and hence dissipation of excess pore pressure, occurs relatively quickly but constitutes only a small fraction of the overall settlement. Secondary compression continues indefinitely but at progressively slower rates. The consolidation behaviour described is similar to that of peat. ${ }^{11}$

The consolidation properties of the sludge improve with increasing levels of digestion. Hence, the efficiency of the mechanical dewatering processes in producing a stiffer sludge cake is improved by more thorough sludge digestion at the wastewater treatment plant. More thorough digestion also reduces the overall dry sludge volume for disposal.

\section{OTHER DESIGN CONSIDERATIONS}

Sludge-to-landfill sites must be designed and managed in such a way as to ensure that no harmful substances reach the biosphere and hydrosphere in unacceptable quantities (in accordance with appropriate national regulations). Containment measures must be engineered and include means to control and treat the leachate and landfill gases. Routine monitoring of the groundwater, surface water and meteorological data is also required to provide assurance that the pollution control measures are working.

\section{SUMMARY AND CONCLUSIONS}

Stricter controls on the quality of wastewater discharges are giving rise to increasing volumes of sewage sludge which are being principally disposed to land or incinerated. Land spreading and in particular sludge-to-landfill methods are 
becoming increasingly utilised, especially in regions which have no municipal waste incineration plants. Current sludge-to-landfill methods generally involve mixing the concentrated sludge with other solid waste in municipal landfills. However, stricter waste disposal legislation and higher landfill taxes are forcing the water industry to look for more efficient disposal strategies. Landfill operators are also unable or increasingly reluctant to accept liquid sludge due to construction difficulties and potential instability of the landfill side slopes.

The feasibility and performance of dedicated sludge-to-landfill disposal operations which maximise the operational life of the landfill site are presented. The method involves dewatering the liquid sludge at the treatment plant to the optimum water content for compaction, transporting the sludge material to the landfill, placing in layers and compacting to the maximum dry density, typically $0.56 \mathrm{t} / \mathrm{m}^{3}$. Sludge handling and compaction operations are most efficiently conducted between typically 85\% water content (WC), the optimum water content for standard Proctor compaction, and 95\% WC (equivalent to approximately $51 \%$ solids content). The liquid sludge can be dewatered to this WC range using the recessed plate filter press device and sludge conditioning, sludge drying beds or thermal drying processes. Substantial reductions in transportation costs are achieved by the drying process.

Stability during construction of the landfill body is generally not a concern since the sludge material has an undrained shear strength of typically $50 \mathrm{kN} / \mathrm{m}^{2}$ over the optimum WC range for compaction. The sludge consistency can be quickly assessed prior to placement in the landfill using the vane shear apparatus. The sludge material is highly compressible but effectively impermeable. Landfill subsidence continues indefinitely but very slowly due to creep and ongoing decomposition of the sludge. Natural evaporation also causes significant shrinkage of the landfill body. The long-term stability of the landfill slopes is analysed using conventional soil mechanics theory and shear strength parameters, presented in the paper, pertinent to the landfill age.

Biologically stabilised sewage sludge is more amenable to dedicated sludge-to-landfill operations: dewatering processes are more efficient; rates of pore water and pore gas generation which can cause landfill instability are reduced, as are volumes of leachate requiring treatment. Dry sludge pellets are generally unsuitable for landfilling since they compact poorly and swell significantly on rehydration, which can lead to landfill instability.

\section{ACKNOWLEDGEMENTS}

The author would like to thank Paul Johnston for his helpful comments during the preparation of this paper.

\section{REFERENCES}

1. Council of European Communities. Directive Concerning Urban Wastewater Treatment (91/271/EEC). Official Journal of the European Communities, 1991, L135/40.

2. Waste Management Acts. Government Publications Office, Ireland, 1996-2003.

3. Metcalf \& Eddy Inc. Wastewater Engineering: Treatment, Disposal and Reuse, 3rd edn. McGraw-Hill, Singapore, 1991.

4. O'Kelly B. C. The geotechnical properties of sewage sludge. Geotechnique, (submitted for publication September 2003).

5. DRoste R. L. Theory and Practice of Water and Wastewater Treatment. John Wiley, New York, 1997.

6. LoLL U. Measurement of laboratory vane shear strength as community standard or reference method for testing the suitability of dewatered sludges for use as landfill. In Treatment and Use of Sewage Sludge and Liquid Agricultural Wastes (L'Hermite P. (ed.)). Elsevier, London, 1991, pp. $310-315$.

7. Holtz W. G. and GibBs H. J. Engineering properties of expansive clays. Transactions, American Society of Civil Engineers, 1956, 121, No. 1, 641-677.

8. Russell H. Race to clear sludge landslide. Institution of Civil Engineers, New Civil Engineer, 20 Feb. 1992, 5.

9. HEAD K. H. Manual of Soil Laboratory Testing, (2) Permeability, Shear Strength and Compressibility Tests (2nd edn). Pentech Press, London, 1994.

10. HEAD K. H. Manual of Soil Laboratory Testing, (3) Effective Stress Tests (2nd edn). John Wiley, London, 1998.

11. HobBs N. B. Mire morphology and the properties and behaviour of some British and foreign peats. Quarterly Journal of Engineering Geology, 1986, 19, No. 1, 7-80.

Please email, fax or post your discussion contributions to the secretary by I March 2005: email: kathleen.hollow@ice.org.uk; fax: +44 (0)20 7799 1325; or post to Kathleen Hollow, Journals Department, Institution of Civil Engineers, I-7 Great George Street, London SWIP 3AA. 